\title{
Transitional antibiotic therapy
}

RICHARD QUINTILIANI MD, Helen M CROWE MD, ChARLES NIGHTINGALE PhD

\begin{abstract}
R Guintiliani, H Crowe, C Nightingale. Transitional antibiotic therapy. Can J Infect Dis 1995;6(Suppl A):6A-10A. With all the fiscal restraints in healthcare systems, it is crucial to develop methods to treat infections that are both clinically sound and cost-effective. Of the various options available, the rapid transition from intravenous to oral therapy represents one of the most effective ways to attain these goals. Moreover, it has the further advantages of shortening hospital stay, reducing nosocomial bacteremia and avoiding the need to rely upon intravenous technicians and equipment. Although there is a need for more patient outcome studies with this approach, the early experience with transitional therapy appears promising.
\end{abstract}

Key Words: Fluoroquinolones, Intravenous to oral therapy, Pseudomonas aeruginosa, Transitional therapy

\section{Traitement antibiotique de transition}

RÉSUMÉ : Compte tenu de toutes les restrictions économiques imposées au système des soins de santé, il est impérieux de mettre au point des méthodes à la fois économiques et cliniquement sensées de traiter les infections. Parmi les diverses options offertes, notons la transition rapide de la voie intraveineuse à la voie orale, qui représente l'une des meilleures façons d'atteindre ce but et qui comporte de plus l'avantage d'abréger le séjour hospitalier, de réduire le risque de bactériémie nosocomiale et d'éviter le recours aux techniciens et au matériel nécessaires. Même s'il faut encore poursuivre la recherche pour déterminer le succès de cette méthode chez les patients, les expériences menées à ce jour semblent prometteuses.

$\mathrm{T}$ HE FOCUS OF PATIENT OUTCOME STUDIES HAS ESSENTIALLY become ways to achieve the best possible clinical outcomes at the lowest cost by utilizing the least amount of hospital resources (eg, drugs, laboratory tests, equipment, personnel time) and doing it with the shortest hospital stay. One of the best ways to achieve this goal is to replace intravenous antibiotic therapy with oral agents as soon as possible.

In 1987, we introduced the term antibiotic 'streamlining' to refer to the process of converting patients from complicated, often expensive, intravenous therapy to equally efficacious, simple, and less expensive regimens (1). When the conversion is from intravenous to oral (iv to po) therapy, the process is now more often designated sequential, transitional, step down or switch therapy.

There are many advantages to employing oral antibiotic therapy in the treatment of infections (Table 1). Significant cost reductions result in the conversion from iv to po therapy because of lower drug acquisition
TABLE 1
Advantages of transitional therapy
Cost reductions, secondary to:
- lower drug acquisition costs
- reduction in pharmacy drug preparation, mixing and dispensing time
- administration of drugs without the need for intravenous technicians and delivery systems
- shorter hospital stays
- reduction in nosocomial infections, especially bacteremia secondary to line sepsis
- reduction in nursing time caring for patients not connected to drug delivery systems
- greater ease in transporting patients for diagnostic studies
- less chance for process errors
Improvement in patient comfort and clinical outcome from:
- more rapid mobilization, which reduces the chances for thrombophlebitis, pulmonary emboli, psychiatric disorders, osteoporosis
- avoidance of painful indwelling intravenous catheters

Divisions of Infectious Diseases / Allergy-Immunology, Hartford Hospital, Hartford, University of Connecticut School of Medicine, Farmington, University of Connecticut School of Pharmacy, Storrs, Connecticut, USA

Correspondence: Dr Richard Quintiliani, Hartford Hospital, 80 Seymour Street, Hartford, CT 06102 USA, telephone 203-545-2878, Fax 203-545-4256 
TABLE 2

Antibiotic transitional program - empiric therapy

\begin{tabular}{|c|c|c|c|}
\hline Infection site & Suspected pathogen & Recommended intravenous drug(s) & $\begin{array}{l}\text { Recommended oral } \\
\text { drug(s) }\end{array}$ \\
\hline Urine & $\begin{array}{l}\text { Enterobacteriaceae } \\
\text { Pseudomonas aeruginosa } \\
\text { Enterococcus }\end{array}$ & $\begin{array}{l}\text { Ampicillin plus } \\
\text { Aminoglycoside }\end{array}$ & $\begin{array}{l}\text { Ofloxacin/Ciprofloxacin } \\
\text { or based on } \\
\text { susceptibility data }\end{array}$ \\
\hline $\begin{array}{l}\text { Lung } \\
\text { (community- } \\
\text { acquired) }\end{array}$ & $\begin{array}{l}\text { Streptococcus pneumoniae } \\
\text { Haemophilus influenzae } \\
\text { Moraxella catarrhalis } \\
\text { Atypicals* }\end{array}$ & 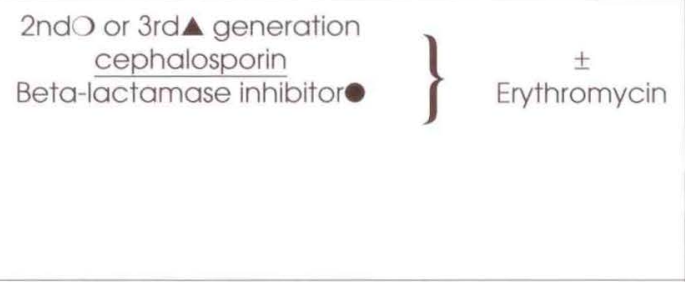 & $\begin{array}{c}\frac{\begin{array}{c}\text { Azithromycin } \\
\text { Clarithromycin }\end{array}}{\text { Ofloxacin/Ciprofloxacin }} \text { plus } \\
\text { Amoxicillin } \\
\text { Cefixime/Cefpodoxime/ } \\
\text { Cefuroxime } \pm \\
\text { Erythromycin }\end{array}$ \\
\hline \multirow[t]{2}{*}{$\begin{array}{l}\text { Lung } \\
\text { (hospital- } \\
\text { acquired) }\end{array}$} & $\begin{array}{l}\text { Staphylococcus/Streptococcus } \\
\text { H influenzae } \\
\text { M catarrhalis } \\
\text { Enterobacteriaceae } \\
\text { Oral anaerobes }\end{array}$ & $\begin{array}{l}\text { 3rd generation cephalosporin } \mathbf{A} \\
\text { TMP-SMX }\end{array}$ & $\begin{array}{l}\text { Ofloxacin or } \\
\text { Ciprofloxacin plus } \\
\text { Clindamycin or } \\
\frac{\text { Amoxicillin }}{\text { TMP-SMX }}\end{array}$ \\
\hline & $\begin{array}{l}\text { Same as above plus } \\
\text { P aeruginosa }\end{array}$ & 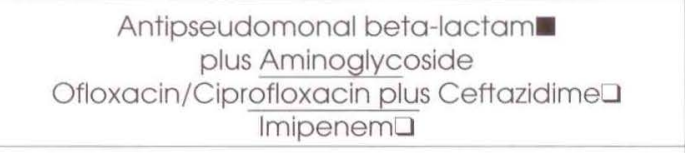 & $\begin{array}{l}\text { Ciprofloxacin/Ofloxacin } \\
\text { plus } \\
\text { Clindamycin }\end{array}$ \\
\hline \multirow{3}{*}{$\begin{array}{l}\text { Skin } \\
\text { Soft tissue } \\
\text { Bone }\end{array}$} & $\begin{array}{l}\text { Staphylococcus aureus } \\
\text { Group A streptococcus }\end{array}$ & Vancomycin & $\begin{array}{l}\text { Cephalexin, } \\
\text { Cephadrine, Cefadroxil }\end{array}$ \\
\hline & $\begin{array}{l}\text { Same as above plus } \\
\text { anderobes, } \\
\text { Enterobacteriaceae }\end{array}$ & Beta-lactamase inhibitor & Amoxicillin-clavulanate \\
\hline & $\begin{array}{l}\text { Same as above plus } \\
\text { P aeruginosa }\end{array}$ & $\begin{array}{c}\text { Antipseudomonal beta-lactamase inhibitor* } \pm \\
\text { Aminoglycoside or Ofloxacin/Ciprofloxacina } \\
\text { plus Ceftazidime } \\
\text { Imipenem] }\end{array}$ & $\begin{array}{l}\text { Ciprofloxacin/ } \\
\text { Ofloxacin } \\
\text { plus Clindamycin }\end{array}$ \\
\hline \multirow[t]{2}{*}{$\begin{array}{l}\text { Abdomen } \\
\text { (community- } \\
\text { acquired) }\end{array}$} & $\begin{array}{l}\text { Enterobacteriaceae } \\
\text { (common), Bacteroides } \\
\text { species, } \\
\text { Staphylococcus/Streptococcus } \\
\text { (treatment or prophylaxis) }\end{array}$ & 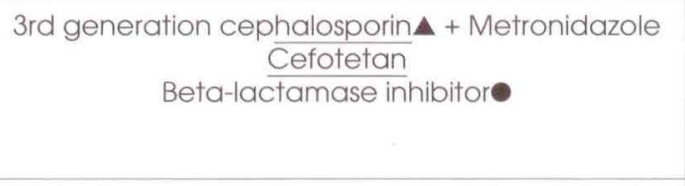 & $\begin{array}{c}\text { Ofloxacin/Ciprofloxacin } \\
\text { plus } \\
\text { Clindamycin } \\
\text { or } \\
\text { Metronidazole }\end{array}$ \\
\hline & $\begin{array}{l}\text { Same as above plus } \\
\text { chlamydia (eg, pelvic } \\
\text { inflammatory disease) }\end{array}$ & Same as above plus Doxycycline & $\begin{array}{l}\text { Ofloxacin plus } \\
\text { Clindamycin or } \\
\text { Metronidazole }\end{array}$ \\
\hline $\begin{array}{l}\text { Abdomen } \\
\text { (hospital- } \\
\text { acquired) }\end{array}$ & $\begin{array}{l}\text { Enterobacteriaceae, } \\
\text { Bacteroides species, } \\
\text { Staphylococcus/Streptococcus, } \\
\text { Enterococcus, P aeruginosa }\end{array}$ & $\begin{array}{c}\text { Antipseudomonas, beta-lactamase inhibitor* } \\
\text { plus Aminoglycoside }\end{array}$ & $\begin{array}{l}\text { Ciprofloxacin/Ofloxacin } \\
\text { plus } \\
\text { Amoxicillin-clavulanate } \\
\text { or Metronidazole }\end{array}$ \\
\hline
\end{tabular}

TMP-SMX Trimethoprim-sulphamethoxazole; "Chlamydia, Mycoplasma, Legionella species; OCefuroxime; $\mathbf{\Delta}$ Cefotaxime, ceftizoxime, ceftriaxone; - Unasyn; Ceftazidime, piperacillin; $\square$ Restricted to infectious diseases physician approval or by protocol; For penicillin allergic patients; * Piperacillin/ tazobactam, ticarcillin/clavulanic acid

costs, a reduction in pharmacy time in the preparation and mixing of drugs, the ability to deliver a drug without the intervention of intravenous technicians, and a reduction in the length of hospital stay. The average daily cost of parenteral antibiotics at Hartford Hospital is at least eight times greater than any oral option.

Perhaps the most important benefit derived from oral antibiotic therapy is the removal of intravenous catheters, which are the major source of nosocomial bacteremia, especially those caused by staphylococci. It has been established that there are more than 20 million vascular catheters inserted annually in patients admitted to hospitals in the United States, resulting in more than 50,000 episodes of bacteremia or line sepsis (2). The frequency of these infections is directly correlated with the duration of their insertion (3). In a recent cost analysis of 104 patients with line sepsis, it was noted that the average additional cost from each episode of line sepsis was US\$3,707, even higher (US\$6,064) if it was caused by Staphylococcus aureus. A number of these episodes, particularly those due to staphylococci, were associated with significant morbidity and occasionally with mortality (4). At our 900-bed hospital, between 1986 and 1988, there were 662 bacteremias, of which 277 (42\%) were caused by Saureus (173 [26\%]) or Staphylococcus epidermidis, (104 [16\%]). Of the 277 
staphylococcal bacteremias, 105 (38\%) were definitely related to line sepsis (ie, organism recovered from both the blood and the catheter). It is quite likely that many of the other staphylococcal bacteremias were a consequence of line sepsis, but the organism was not grown from the catheter. Using a figure of $\$ 4,000$ in extra costs per definite episode of line sepsis, our additional health care cost from this problem was approximately US\$420,000 over the three year period, not including the cost of line sepsis from other organisms.

One of the major reasons for mistakes in intravenous drug administration is so called 'process error'. The director of our pharmacy services tabulated more than 20 steps or processes that must be followed before an intravenous drug is actually administered to a patient once a physician writes an order. These processes involve interpretation of the physician's order by ward clerks, nurses, intravenous technicians, and then often rewriting it on other forms, where again the process of rechecking and countersignatures is needed. Before the drug can be given, it must be delivered to the ward and then often remixed by technicians who may then encounter problems with insertion of the catheter into a vein, further increasing the chances for infection and patient discomfort.

Because of the absence of cumbersome intravenous delivery systems, patients are more easily mobilized on oral therapy, again reducing the possibility of other hospital-related problems such as deep vein thrombophlebitis, pulmonary emboli, depression and adverse drug reactions.

\section{FLUOROQUINOLONES}

Physicians have always been sceptical of treating serious infections with oral antibiotics because of the possibility of incomplete absorption from the intestine, which can result in suboptimal concentrations at the site of infection. The fluoroquinolones have gained considerable attention as excellent transitional choices because they are well absorbed, penetrate readily into tissue, exhibit a high degree of microbiological activity against many unusual and common pathogens, and have a long half-life (5-7). There are considerable similarities between aminoglycosides, like gentamicin and tobramycin, and the fluoroquinolones. For instance, like the aminoglycosides, both ciprofloxacin and ofloxacin are highly active against most Enterobacteriaceae and Pseudomonas aeruginosa, moderately active against staphylococci and streptococci, and poorly active against anaerobes and enterococci. These microbiologic gaps in the activity of fluoroquinolones can be filled in part or in total by several well-absorbed antibiotics. For instance, clindamycin, which is highly active against anaerobes and streptococci, is more than 90\% absorbed; metronidazole, which inhibits essentially all Bacteroides species, is almost 100\% absorbed; and amoxicillin-clavulanate, which is reliably active against most enterococci, streptococci and anaerobes, is about $70 \%$ absorbed.

In Table 2, we present a transitional quinolone program developed at Hartford Hospital. It is based on the usual suspected pathogens in a variety of common clinical problems, such as hospital-acquired and community-acquired infections of the lung, abdomen, urine and skin. In an attempt to recognize many of the common parenteral choices selected by infectious disease physicians in these conditions, we tabulated a variety of popular choices in each category. The preference of ofloxacin over ciprofloxacin in pelvic inflammatory disease relates to the higher clinical efficacy of ofloxacin compared with ciprofloxacin in the treatment of chlamydia urethritis or cervicitis; in fact, ofloxacin $300 \mathrm{mg}$ bid for one week has been shown to be as successful as $100 \mathrm{mg}$ doxycycline bid for one week. Against Pseudomonas aeruginosa, ciprofloxacin exhibits significantly more intense activity (MIC90 $0.5 \mu \mathrm{g} / \mathrm{mL}$ ) compared with ofloxacin (Mic90 $2.0 \mu \mathrm{g} / \mathrm{mL}$ ) and, hence, it is tempting to prefer ciprofloxacin over ofloxacin in any situation in which this bacterium is a proven or highly suspected pathogen. In the urine this difference in microbiologic activity has no clinical relevance, for the levels of both fluoroquinolones are so high in that site. It should be recalled that ofloxacin's major elimination is via the kidney and, as a result, the urinary concentrations of this drug are even greater than those of ciprofloxacin.

In systemic pseudomonal infections in seriously ill, clinically unstable patients, monotherapy with any parenteral antibiotic is probably not advisable. As with other monotherapies, the use of ciprofloxacin by itself has been associated with the emergence of resistant isolates and suboptimal clinical responses and frequent need to modify the initial monotherapy (8-10). Similar selection of ciprofloxacin-resistant strains of $P$ aeruginosa have been observed in in vitro models of infection (11). Most infectious disease physicians treat patients of this type with the combination of an antipseudomonal aminoglycoside (eg, gentamicin, tobramycin) and an antipseudomonal beta-lactam agent (eg, ceftazidime, piperacillin, ticarcillin/clavulanate, piperacillin/tazobactam).

More data are needed on the relative difference in activity of ciprofloxacin and ofloxacin in combination with these and other antipseudomonal drugs. In vitro, ciprofloxacin in combination with piperacillin exhibits either additive or synergistic effects. Stratten et al (12) showed that combinations containing ciprofloxacin and beta-lactam drugs were synergistic for isolates of $P$ aeruginosa that were susceptible to both agents and that the combination prevented the emergence of resistance to either drug.

Compared with ciprofloxacin, ofloxacin has a number of favourable attributes: better oral bioavailability (100\% versus 70\%), greater Gram-positive bacterial 
and chlamydia activity, no significant interaction with xanthines (eg, theophylline, theobromine, caffeine), preferable pharmacokinetics (longer half-life, higher peak serum concentrations) and higher levels in urine. Although ofloxacin exhibits significantly less intense microbiologic activity against $P$ aeruginosa (MIC 2.0 versus $0.5 \mu \mathrm{g} / \mathrm{mL}$ ), the clinical significance of this difference remains controversial. Since the urinary concentrations of both drugs far exceeds their MIC for $P$ aeruginosa, either agent can be used with equal efficacy in the treatment of a urinary tract infection from this bacteria or any other susceptible organism. However, in pseudomonas infections involving other body sites (eg, bone, ear, skin, soft tissue), clinically stable patients who can take oral drugs should probably receive ciprofloxacin because its AUC above the MIC for $P$ aeruginosa exceeds that of oral ofloxacin, yet excellent clinical results have also been obtained with oral ofloxacin, even when infections in these sites have been caused by this organism (13). Since the AUC above the MIC for $P$ aeruginosa after a single $750 \mathrm{mg}$ dose of oral ciprofloxacin even exceeds that following a single $400 \mathrm{mg}$ intravenous dose, and since the AUC of a $400 \mathrm{mg}$ dose of ofloxacin is identical to a $400 \mathrm{mg}$ intravenous dose (ie, 100\% absorption), it makes good pharmacoeconomic sense to use these quinolones by mouth whenever possible to lower cost markedly and avoid the risk of intravenous catheter sepsis.

In a recent human volunteer four-way crossover study (14), we found that neither a $400 \mathrm{mg}$ intravenous dose of ciprofloxacin nor ofloxacin yielded adequate serum bactericidal titres against $P$ aeruginosa over a $12 \mathrm{~h}$ period, suggesting that monotherapy with either agent should not be relied upon to treat serious systemic pseudomonas infection. Interestingly, when either quinolone was combined with ceftazidime (1 g intravenously every $8 \mathrm{~h}$ ), the serum bactericidal titres improved in a similar fashion supporting the notion that combination with a beta-lactam overcame MIC differences between the two drugs. Clinical experience with the combination of a quinolone and a beta-lactam, however, is meagre compared to that with an antipseudomonal beta-lactam and aminoglycoside combination. Moreover, costs of aminoglycosides are much lower than the intravenous quinolones, particularly if once daily dosing is used, and less burdensome on ancillary service time.

The use of oral therapy in the treatment of soft tissue and bone infections, particularly in patients with peripheral vascular disease or diabetes mellitus, or both, is attractive because these infections typically require prolonged therapy, often for weeks or months. Although clinical data remain meagre, several studies $(13,15,16)$ have shown favourable clinical outcome in many patients with these problems.

There have been surprisingly few studies done on the pharmacokinetics of oral fluoroquinolones in sick, hos- pitalized patients who have been converted from intravenous to oral therapy. We recently performed a study of the bioavailability of oral ciprofloxacin $(750 \mathrm{mg}$ qid every $12 \mathrm{~h}$ ) in 25 hospitalized patients who were switched from various intravenous antibiotic regimens to this drug (17). Of the 25 patients in this study group, 20 had pharmacokinetic parameters similar to those of healthy volunteers. Of the five patients with suboptimal absorption, four were receiving medications that contained high amounts of divalent or trivalent cations, while one patient was taking ursodiol. We restudied the patient on ursodiol and confirmed that this drug definitely interferes with the absorption of ciprofloxacin (18).

In our study and in others $(19,20)$, the drug interaction of greatest potential is between oral fluoroquinolones and medications (eg, antacids, sucralfate) containing high concentrations of divalent and trivalent cations (calcium, magnesium, aluminum, iron, zinc). Of potential clinical concern is the observation that both ciprofloxacin (21) and ofloxacin (22) exhibit reduced absorption if given two to three days post chemotherapy.

Another common reason why physicians are reluctant to convert to oral therapy is that this change often results in pressure on them from utilization review committees and insurance companies to discharge the patient. Indications for stay should be considered independent of the mode of drug therapy, and this is an unfortunate circumstance. In fact, the replacement of any intravenous drug with an oral agent should be viewed as one of the most effective ways to reduce cost and overutilization of hospital personnel and resources. Fortunately, there finally is an awareness of this view since InterQual, a company that establishes criteria or guidelines for many utilization review committees in the United States hospitals, recently stated that a patient's severity of illness index should not be reduced merely on the basis of change from an intravenous to an oral antibiotic.

Given the widespread, inveterate popularity of intravenous therapy for serious infections, physicians will not readily make the transition to oral therapy unless they can be convinced that oral therapy is as efficacious as parenteral therapy and that the drugs are well absorbed in patients with various disease states, on other medications, or who have had recent gastrointestinal surgery. Moreover, whether the greater use of quinolones in hospitals may create more bacterial resistance remains to be determined. In short, more clinical and epidemiologic studies are needed to compare the clinical outcome and bacteriologic response of parenteral versus oral therapy, and more pharmacokinetic studies are required to compare the bioavailability of oral drugs in healthy versus sick people. Nevertheless, the early results with transitional therapy appear promising for cost containment and reduction in nosocomial infection, without compromising clinical efficacy. 


\section{REFERENCES}

1. Guintiliani R, Cooper BW, Briceland LL, Nightingale $\mathrm{CH}$. Economic impact on streamlining antibiotic administration. Am J Med 1987;82(4A);391-4.

2. Maki DG. Infection due to infusion therapy. In: Bennett JV, Brachman PA, eds. Hospital Infection. Boston: Little, Brown, 1986:561-80.

3. Read I, Body GP. Infectious complications of indwelling vascular catheters. Clin Infect Dis 1992;15:197-210.

4. Arnow PM, Quimosing EM, Beach M. Consequences of intravascular catheter sepsis. Clin Infect Dis $1993 ; 16: 778-84$.

5. Fernandes PB. Mode of action and in-vitro activity of the fluoroquinolones. J Clin Pharmacol 1988;28:156-68.

6. Forsgren A. Overview of Scandinavian in-vitro studies with ciprofloxacin. Scand J Infect Dis 1988;(Suppl $60): 16-22$.

7. Nix DE, Schentag JJ. The quinolones: an overview and comparative appraisal of their pharmacokinetics and pharmacodynamics. J Clin Pharmacol 1988;28:169-78.

8. Johnson P, Liv Uin JA, Tooth JA. High dose intravenous ciprofloxacin in febrile neutropenic patients. J Antimicrob Chemother 1990;(Suppl 26):101-7.

9. Boyston KF, Want S, Cohen J. A prospective randomizing comparison of ceftazidime and ciprofloxacin as initial empiric therapy in neutropenic patients with fever. Am J Med 1989;(Suppl 5A);269S-73S.

10. Meunier F, Zinner SH, Goya H, et al. Prospective randomized evaluation of ciprofloxacin versus piperacillin plus amikacin for empiric antibiotic therapy of febrile granulocytopenic cancer patients with lymphomas and solid tumors. The European Organization for Research on the Treatment of Cancer. International Antimicrobial Therapy Cooperative Group. Antimicrob Agents Chemother 1991;35:873-8.

11. Marchbanks CR, McKiel JR, Gilbert DH, et al. Dose ranging and fractionation of intravenous ciprofloxacin against Pseudomonas aeruginosa and Staphylococcus aureus in an in-vitro model of infection. Antimicrob Agents Chemother 1993;37:1756-63.

12. Stratton CW, Franke JJ, Weeks LS, Manion FA. Comparison of the bactericidal activity of ciprofloxacin alone and in combination with selected antipseudomonal $\beta$-lactam agents against clinical isolates of Pseudomonas aeruginosa. Diagn Microbiol Infect Dis 1989;11:41-52.

13. Gentry LO, Rodriguez-Gomez G. Ofloxacin vs parenteral therapy for chronic osteomyelitis. Antimicrob Agents Chemother 1991;35:2371-4.

14. Klepser ME, Patel KB, Nicolau DP, Quintiliani R, Nightingale $\mathrm{CH}$. Comparison of the bactericidal activities of ofloxacin and ciprofloxacin alone and in combination with ceftazidime and piperacillin against clinical strains of Pseudomonas aeruginosa. (In press).

15. Peterson LR, Lissak LM, Canter K, et al. Therapy of lower extremity infections with ciprofloxacin in patients with diabetes mellitus, peripheral vascular disease or both. Am J Med 1989;86:801-7.

16. Gentry LD, Rodriguez-Gomez GG. Oral ciprofloxacin compared with parenteral antibiotics in the treatment of osteomyelitis. Antimicrob Agents Chemother 1990;34:40-3.

17. Belliveau P, Nightingale CR, Quintiliani R. Bioavailability and cost-analysis of hospitalized patients converted from intravenous regimens to oral ciprofloxacin. Sixth European Congress of Clinical Microbiology and Infectious Diseases. Seville, Spain, March 28-31, 1993. (Abst 701)

18. Belliveaue PP, Nightingale $\mathrm{CH}$, Quintiliani R, Maderazo E. Reduction in serum concentrations of ciprofloxacin after administration of ursodiol to a patient with hepatobiliary disease. Clin Infect Dis 1994; 19:354S.

19. Polk RE. Drug-drug interactions with ciprofloxacin and other fluoroquinolones. Am J Med 1989;87(Suppl):76S-81S.

20. Stein GE. Drug interaction with fluoroquinolones. Am J Med 1991;91(6A):81S-6S.

21. Johnson EJ, MacGowan AP, Potter MN, et al. Reduced absorption of oral ciprofloxacin after chemotherapy for hematological malignancy. J Antimicrob Chemother 1990;25:827-42.

22. Brown NW, White LO, Blundell E, et al. Absorption of oral ciprofloxacin after chemotherapy for hematological malignancy. J Antimicrob Chemother 1993;32:117-22. 


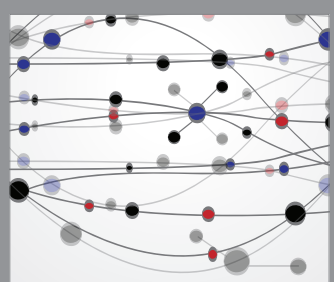

The Scientific World Journal
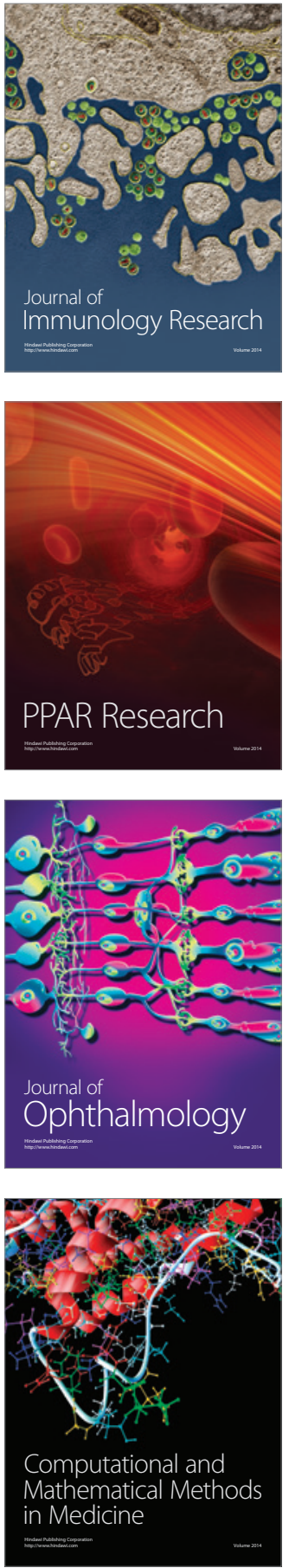

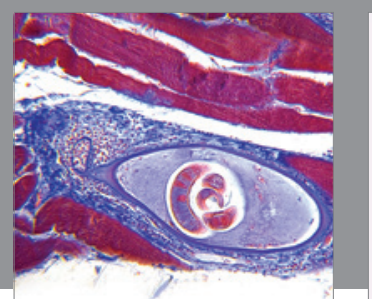

Gastroenterology Research and Practice

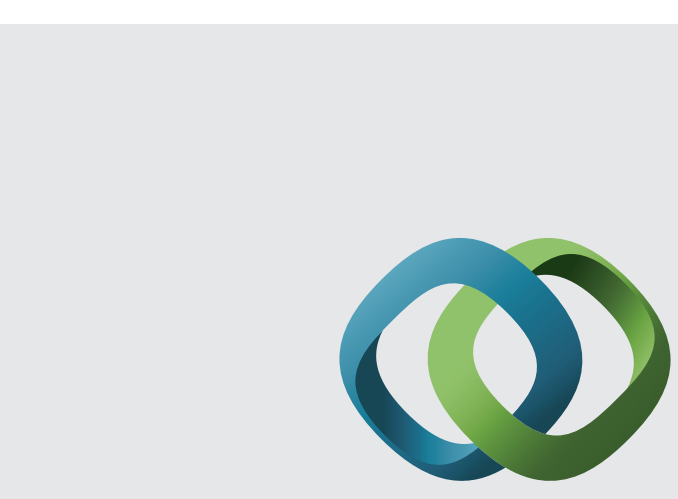

\section{Hindawi}

Submit your manuscripts at

http://www.hindawi.com
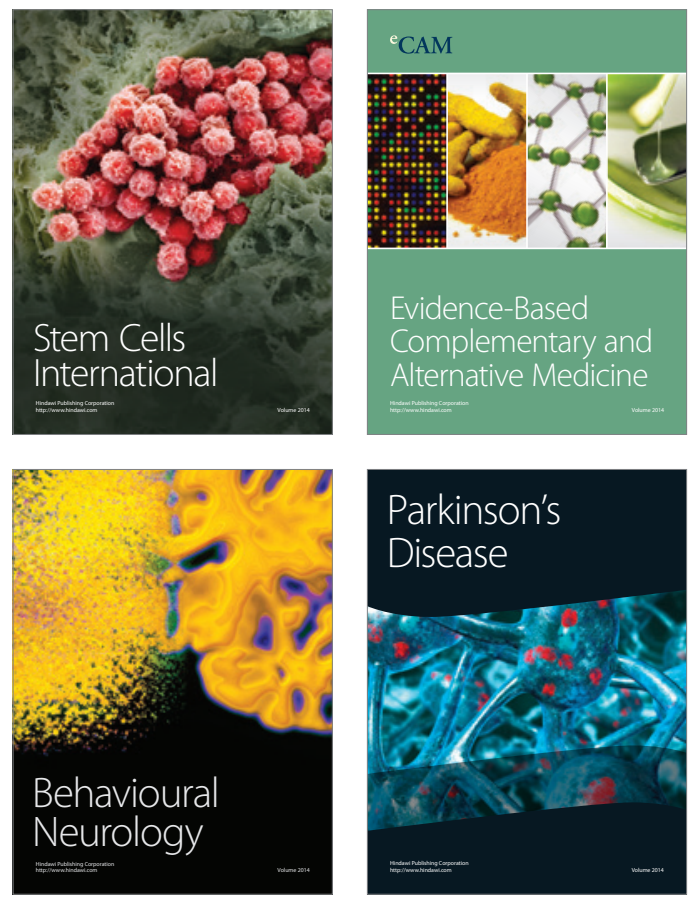
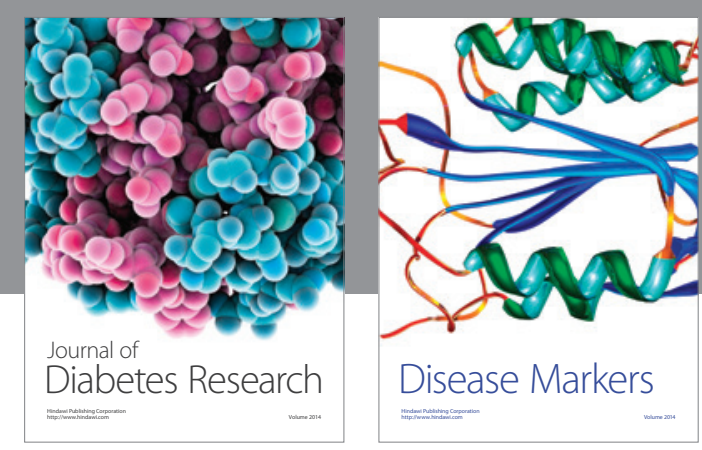

Disease Markers
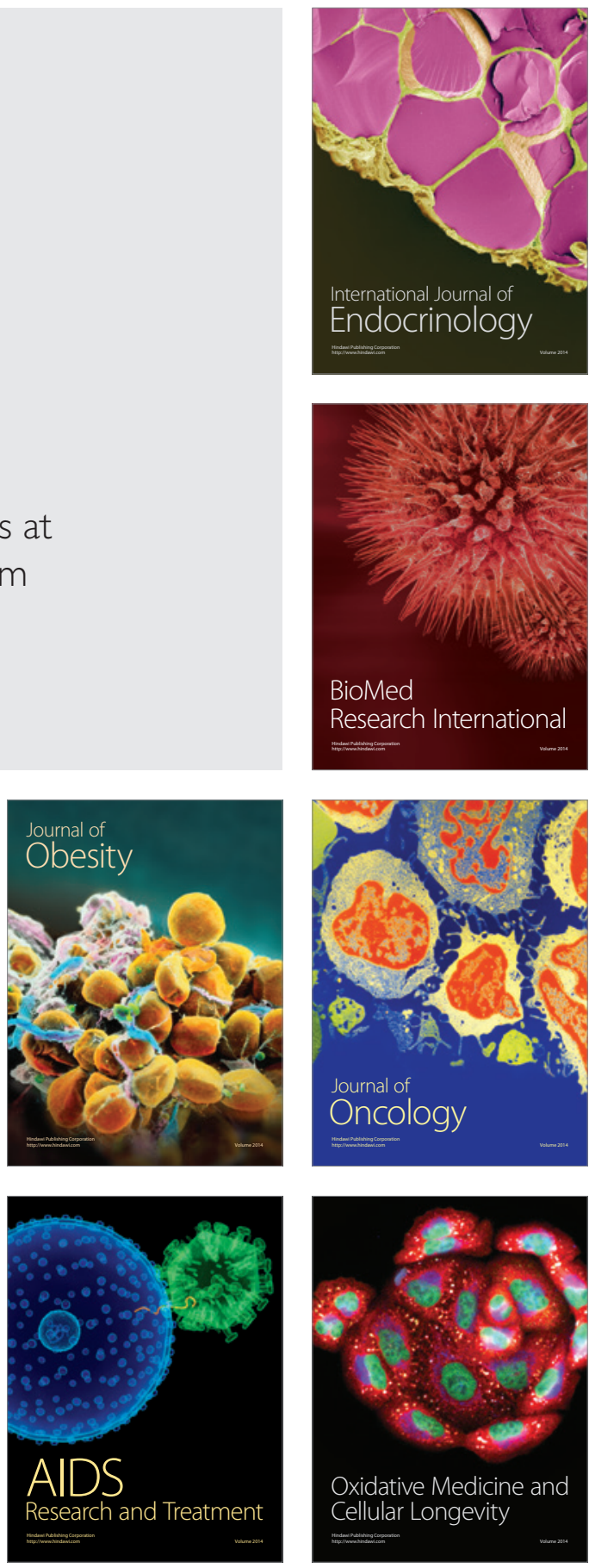